\title{
Robert A. Karl. La paz olvidada. Políticos, letrados, campesinos y el surgimiento de las FARC en la formación de la Colombia contemporánea. Bogotá:
}

Librería Lerner, 2018, 425 pp.

Renán Silva*

T a paz olvidada es un libro importante desde muchos puntos de vista. El principal L propósito de este trabajo es "restablecer las cargas" sobre un problema esencial: en la historia de Colombia no solo el conflicto armado ha sido importante, también lo ha sido la paz. El objetivo es saludable y cuenta hoy con mejor ambiente, pues en la actualidad la opinión académica que afirma esa proposición ya no es la de una simple minoría de estudiosos cuyo pensamiento se estimaba hasta ayer simplemente como la expresión de su "reformismo" y de su falta de "compromiso" con el país.

La pregunta esencial que puede plantearse un lector es por qué el peso fundamental que adquirió esa unilateral representación de la historia, punto sobre el que investiga de manera documentada la obra. Robert Karl plantea un asunto que me parece dificil de controvertir, por más que se pueda matizar: el peso exagerado que la opinión de cierto grupo de "hombres de letras", casi siempre académicos reconocidos y juiciosos investigadores, ha tenido como voz pública y autorizada sobre el problema.

Relacionado con lo anterior, se encuentra otro aspecto esencial, pero que no tiene las implicaciones políticas directas de la idea de que paz y violencia han estado más entreveradas en la historia nacional de lo que se ha pensado, aunque sí gran importancia en términos analíticos. Se trata del planteamiento según el cual la historia de Colombia es menos excepcional de lo que se ha repetido por mucho tiempo. La propuesta del libro es aún más compleja, porque no solo sostiene que hay muchos elementos comunes en la historia del siglo XX colombiano con el subcontinente americano, sino que afirma que en cierta manera Colombia vivió con adelanto situaciones que los países del Cono Sur conocerían más tarde, respecto a las cuales produjo esbozos originales de solución que por desgracia

* Investigador del Centro de Estudios en Historia de la Universidad Externado de Colombia. 
pronto fueron olvidados. El autor se refiere a los asuntos relacionados con la reconciliación, con el perdón y el olvido, así como con los problemas de la memoria histórica como centro de reflexión y con una serie muy variada de experiencias colombianas locales a finales de los años cincuenta, que en la vitrina de la opinión internacional y en la propia memoria de las ciencias sociales se mencionan y recuerdan siempre como una originalidad de los países del Cono Sur en la época de las posdictaduras, con desconocimiento total de que experiencias de esa naturaleza habían tenido un laboratorio de elaboración y reflexión temprano en Colombia.

Hay que reconocer que los puntos de la memoria, la reconciliación, el perdón, el olvido y otras originalidades en cuanto a tribunales de solución de conflictos, asuntos sobre los que insiste la obra, que fueron distintivos de los años de transición hacia la democracia al final de la dictadura de Rojas Pinilla y en el mandato de Alberto Lleras, habían sido poco mencionados por lo que se refiere a su significación y a sus posibilidades como formas de buscar el fin de conflictos sociales y sus derivaciones armadas. Esta es una de las mejores contribuciones de este trabajo al conocimiento de la historia de Colombia.

Los análisis del libro en esta dirección se concretan en la idea de que la "violencia no puede ser el único registro en que grabemos el pasado nacional", como dice el autor en las páginas iniciales del libro, sin que ello signifique una actitud de negación frente al peso de la violencia en la historia del país. Como dijimos al principio, la proposición busca ante todo "equilibrar las cargas", no negar la presencia de la violencia.

El autor admite, desde luego, que lo que presenta es una interpretación, y no simplemente la interpretación a la que en adelante todos deberíamos acogernos; pero como no se trata de una obra que se inscriba en el relativismo extremo, y mucho menos en el cinismo, Karl declara su confianza en que su argumentación sea convincente para los lectores, y ofrece como agregado a la garantía de la corrección de sus tesis el hecho de que su trabajo ayuda a explicar "cómo surgieron otras interpretaciones que durante largo tiempo han predominado en el panorama intelectual".

Un punto notable del libro es el trabajo conceptual, la proposición de categorías de gran alcance teórico e histórico, formuladas a través del vocabulario de la época y aun del lenguaje más corriente, aunque desde luego precisado y redefinido. Me refiero a las dos categorías mayores del análisis, derivadas del conocimiento del periodo histórico estudiado. En primer lugar, convivencia, una categoría de análisis que es al mismo tiempo la puesta de presente de una de las grandes aspiraciones sociales de esos años. Según el autor, convivencia es una palabra que traduce sobre todo "una visión específica de la pertenencia cívica y la prosperidad material...". En segundo lugar, paz criolla, que trata de reunir todas las experiencias históricas, locales, regionales y nacionales, de búsqueda de la paz y la convivencia, tal como se manifestaron a finales de los años cincuenta. ${ }^{2}$

2. Señalemos, de paso, que para la edición en castellano el autor y los editores han tomado la decisión de incluir lo que en la edición original deben haber sido las páginas de "enfoque" conceptual del trabajo, de tal manera que el lector que deseé concentrarse desde el principio en 
Asimismo presenta como tercera categoría lo que constituye la delimitación espacial. Es un punto de alta elaboración de este trabajo no solo por lo que significa en cuanto a la definición de escalas de análisis — una multiplicación de planos que se combinan de manera sorprendente-, sino aún más en cuanto al establecimiento de su propia espacialidad: elTolima Grande, no definido en términos "administrativos-departamentales", sino a la manera de una amplia región que se redefine en el curso mismo de la obra (se amplía, sí, pero también se contrae en la narración, porque así ocurrió en el proceso que se narra). Lo que deja planteada la necesidad para investigaciones futuras de no definir su espacio en términos de unidades administrativas, como tantas veces se ha hecho: Quindío, el propio Tolima, Antioquia.Además, hay muchos otros ejemplos de obras que han tomado la vía de delimitar una unidad administrativa como una región social y política, un camino de método que en el futuro habrá que revisar, siguiendo el ejemplo de este libro que delimita el llamado Tolima Grande como una "macrorregión del valle del alto Magdalena”, centro y sur de Colombia, que junta los departamentos de Tolima, Huila, partes del Cauca, Meta y Caquetá, pero que es ante todo la definición de un espacio que se modifica en función de los actores y del conflicto, así como de las apuestas que cada uno de ellos —o todos ellos - realizan como parte de sus estrategias. De paso, anotemos que Karl menciona una soberbia intuición de Michael Taussig sobre las dificultades que implica pensar el espacio de la sociedad colombiana, de manera particular el que ha sido dominante en el conflicto que la obra estudia. Según Taussig, hay necesidad de pensar el espacio andino bajo nuevas formas, y menciona la manera como en el caso colombiano "el espacio dilata la experiencia del tiempo".

El autor posee una cualidad básica que todo historiador debería tener y que uno extraña tanto en la mayor parte de los libros de historia sobre Colombia: una gran sensibilidad por las palabras, un tratamiento respetuoso del lenguaje de la época, un cuidado extremo por no introducir vocablos que la época ignoraba, como un camino sabio para evitar los casos más flagrantes de anacronismo. No solo presta atención al lenguaje, sino que se muestra capaz en el análisis de seguir de cerca cada uno de los vocablos claves que se utilizan en la narración del proceso, empezando, por ejemplo, por el término "violencia”, en todas sus significaciones, y en todos sus cambiantes matices. En buena medida, parte de la tesis del libro sobre el papel de los letrados en la representación desequilibrada de las relaciones entre la paz y la violencia en la historia de Colombia viene de un seguimiento cuidadoso de la forma como la palabra "violencia" se ha modificado, y del estudio de quiénes han sido los actores de la modificación, en qué situaciones y con cuáles efectos.

Según Karl, los letrados -académicos, sobre todo- han impuesto una representación exagerada del papel de la violencia en la historia de Colombia. Creo que la tesis no solo es cierta, sino que las voces que sostenían una posición

la historia narrada puede eludir esas páginas "académicas" y volver a ellas al final, si así lo desea, encontrando ampliaciones mayores de las categorías básicas que organizan la narración que se presenta en el cuerpo de la obra. 
matizada fueron más numerosas de lo que parece pensar el autor, lo que conduce de nuevo a la pregunta de por qué el éxito de esa opinión. ¿A qué específica demanda, sobre todo universitaria, se acoplaba como "anillo al dedo" esa respuesta? Es claro que, con independencia de los mejores deseos de quienes transformaron esa visión en una representación que se impuso a buena parte de la sociedad, ha sido una justificación desde hace medio siglo para los grupos que tomaron el camino armado y que declararon que "las elecciones son una farsa", la "democracia una mentira", el Frente Nacional una simple exclusión. Pero habría que seguir en detalle todas las formas de reproducción cultural que le dieron tal eco a esa tesis y la volvieron incluso una forma de representación de la nación acogida por buena parte del teatro colombiano, de sus artes plásticas y de su novelística, y que produjeron una situación de reproducción circular en la cual ya no se sabe cómo y cuándo comenzó esa manera de considerar los problemas. Además, habría que investigar con todo cuidado si en principio esa representación de derrota histórica no fue una prolongación de un gran sentimiento nacional colectivo, en la medida en que los procesos de rehabilitación y reconciliación de la década de 1950 se fueron al traste. Si este fuera el caso, habría que señalar también que los investigadores de las ciencias sociales y los artistas autodesignados como "comprometidos" no tuvieron la capacidad de "tratar y elaborar" esa representación para mostrar que ella era cierta, pero unilateral y desesperanzadora, y que siempre habrá caminos para intentar la paz.

Queda por confirmar, ampliar o refutar la sustentación que ofrece Karl sobre los elementos de vida personal, de vida colectiva y de teoría que ampararon y adornaron esa interpretación en el campo académico. Me parece que en ese punto las preguntas siguen abiertas y lo que tenemos es una primera respuesta. Esperemos que el planteamiento sirva por lo menos para volver a discutir el problema, más allá de los lugares comunes que hasta ahora han dominado.

El autor es consciente de que en la actualidad Colombia pasa por una etapa en las relaciones entre acuerdos de paz y permanencia de los viejos conflictos armados que recuerda la historia que el libro narra, y que la opción de la "violencia" sigue ahí, pero que se trata de una posibilidad que se puede derrotar. Se trata claro de una empresa realmente difícil porque hoy las condiciones son más complejas que a finales de los años cincuenta: comercio de drogas, guerrillas que son ya hoy empresas criminales a las que la paz simplemente sacaría de su "zona de confort", minería ilegal, entre otros. Estamos muy lejos de las escopetas con las que las gentes de Marquetalia iniciaron sus acciones de defensa, y cuyo encuentro veinte años después con el comercio de droga produjera el desastre que eran las FARC al final de su camino, por fortuna hoy abandonado. La empresa de la paz es hoy más dificil que ayer y está lejos de haber sido ganada, pero una de las condiciones de la derrota de la guerra es vencer la consideración de que la violencia es ineluctable para el país, porque constituye su más grande tradición.

Me parece importante recomendar la lectura de La paz olvidada, pues creo que su significado político y académico va mucho más allá del que habitualmente 
podría ser el de una buena tesis doctoral, hecha con rigor y con atención por los datos y por el análisis, y que muestra además un conocimiento cuidadoso de la amplia bibliografia existente sobre el problema.

Se trata de un libro que invita a volver a pensar en el valor de las palabras y pone de presente un ángulo de la noción de compromiso sobre el que poco se habla, como si los especialistas en la palabra fueran, por raro que parezca, poco sensibles a la propia materia que utilizan. Me refiero al compromiso con la palabra y con el análisis, centro de nuestro trabajo como investigadores. En Colombia se ha entendido de manera tradicional como "compromiso con los pobres" o con el "cambio de las estructuras", pero los productores de análisis parecen haber sido poco conscientes del compromiso que implica lo que producen para la opinión pública o académica. Encerrados en su gran idea de "compromiso social", por el camino se han dejado enredar en estados de ánimo —exaltaciones y desilusiones que se cuentan en la obra de Karl-, o se han afirmado en visiones indiscutidas que al final han terminado siendo su propia trampa, y han dejado en el olvido el compromiso esencial con las ideas. Inquietos por lo "social" y dedicados a la "causa", que también produce sus prestigios y otorga autoridad, pueden que hayan dejado de lado la idea de la autosubversión, en el sentido de Albert Hirschman, y hayan estado poco dispuestos a examinar de manera crítica sus propios análisis, los que, sobre todo en la generación de "violentólogos" recientes, mucho más que en sus antecesores, terminaron constituidos en un pequeño patrimonio que se ha tratado a todo precio de conservar.

DOI: $10.17533 /$ udea.trahs.n15a08 